\title{
Bruck syndrome: A rare case presentation with isolated lower extremity contractures and multiple postoperative peri-implant fractures
}

\author{
Gunjar Jain ${ }^{1}$, Rameshwar Datt ${ }^{2}$, Vijay Sharma ${ }^{3}$, Kamraan Farooque ${ }^{3}$, Rahul Morankar ${ }^{4}$, Anant Krishna ${ }^{1}$ \\ From ${ }^{1}$ Assistant Professor, Department of Orthopaedics, SGT Medical College Hospital and Research Institute, Gurgaon, Haryana, ${ }^{2}$ Senior Resident, \\ ${ }^{3}$ Professor, ${ }^{4}$ Assistant Professor, Division of Pedodontics, Centre for Dental Education and Research, Department of Orthopaedics, All India Institute \\ of Medical Sciences, New Delhi, India
}

\begin{abstract}
Bruck syndrome, characterized by congenital brittle bones and multiple joint contractures, is a rare variant of osteogenesis imperfecta. Here, we report the case of a 7-year-old male patient who presented with a fractured shaft of the femur following trivial trauma. He was a diagnosed case of arthrogryposis multiplex congenita with deformities involving both knees and ankle. He had a history of bilateral femoral fractures during birth. Due to the knee contracture and a narrow canal, we fixed the fracture by plating. However, the patient developed peri-implant fractures proximal to the plate. Due to the presence of multiple peri-implant fractures and joint contractures, we diagnosed the patient with Bruck's syndrome and initiated intravenous bisphosphonate therapy. Subsequently, the patient developed one more fracture in the contralateral femur. This case signifies the importance of screening all patients with multiple congenital contractures and recurrent fractures for Bruck syndrome.
\end{abstract}

Keywords: Bruck syndrome, Osteogenesis imperfecta, Recurrent fracture, Arthrogryposis multiplex congenita

$\mathrm{O}$ steogenesis imperfecta is the most common genetic disorder affecting the musculoskeletal system [1]. Bruck syndrome is one of the rare autosomal recessive variants of osteogenesis imperfecta, characterized by joint contractures with pterygium and multiple recurrent fractures [2]. It has been classified into two types, Type-1 Bruck syndrome is caused by FKBP10 mutations, whereas, PLOD2 mutations cause type 2 Bruck syndrome [3]. However, phenotypically these types are indistinguishable [3]. The presentation may vary from mild to severe lethal disease. Characteristic clinical features of osteogenesis imperfecta such as blue sclera, hearing loss, dentine abnormality may or may not be seen in Bruck syndrome. There are very few reported cases of Bruck syndrome in the literature.

We present a case of Bruck syndrome with isolated involvement of the lower extremities.

\section{CASE REPORT}

A 7-year-old male child presented to our emergency department with chief complaints of pain and swelling in the right thigh for 1 day following a trivial fall from the bed of two feet height

\section{Access this article online}

Received - 26 September 2021

Initial Review - 13 October 2021

Accepted - 19 October 2021

DOI: $10.32677 /$ ijcr.v7i11.3101 while sleeping. The patient was a known case of arthrogryposis multiplex congenita with congenital contractures involving both the knees and ankle. Because of the lower limb deformities, he was wheelchair dependent. There was no history of any previous low-energy fractures except for the bilateral femoral fracture sustained during birth (Fig. 1a). The patient was a full-term child delivered vaginally with a birth weight of $3 \mathrm{~kg}$ and had cried immediately after birth. His parents had a consanguineous marriage with two children. None of his first or second-degree relatives, including his elder brother, had similar complaints. $\mathrm{He}$ had received all immunization as per the national immunization schedule. One year back, he had received serial corrective castings for the knees contractures in another hospital. Even after 2 months of these weekly casts, he did not have any improvement.

On examination, the patient had an isolated injury to his right thigh and was conscious and oriented with normal cognition. There was swelling, tenderness, and abnormal mobility, over the right thigh without any distal neurological deficit. The patient had flexion contractures of $100^{\circ}$ and $105^{\circ}$ at the right and left knee, respectively. Pterygium was present at bilateral knees. Both ankles had plantar flexion deformities due to contracture of the tendoachilles. The ocular sclera was white, the dentine was healthy, and there was no hearing loss or any abnormal facial

Correspondence to: Rameshwar Datt, Department of Orthopaedics, All India Institute of Medical Sciences, Ansari Nagar, New Delhi - 110 049, India. E-mail: rameshwar5189@gmail.com

(C) 2021 Creative Commons Attribution-NonCommercial 4.0 International License (CC BY-NC-ND 4.0). 
features (Fig. 1b). No contracture, deformity, or anomaly was present in the upper limbs, chest, spine, and genitalia.

The radiograph of the right thigh showed a mid-shaft fracture of the femur (Fig. 2a). The bone was osteoporotic and had a very narrow diaphysis. The skull $\mathrm{X}$-ray showed the presence of Wormian bones (Fig. 2b), and the X-rays of the knees showed flexion deformity (Fig. 3). The spine radiograph did not show the presence of any deformity. His routine laboratory parameters and the indices of calcium metabolism were within normal limits (Serum Vitamin D3 - $58.1 \mathrm{ng} / \mathrm{ml}$, Parathyroid hormone - $9.3 \mathrm{pg} / \mathrm{ml}$, Serum total Calcium - $10 \mathrm{mg} / \mathrm{dl}$, serum Phosphate - $5.3 \mathrm{gm} / \mathrm{dl}$, and Alkaline phosphatase - $504 \mathrm{IU} / \mathrm{L}$ ). His bone mineral density, estimated using a dual-energy X-ray absorptiometry scan at the first and second lumbar vertebrae, was $0.54 \mathrm{gm} / \mathrm{cm}^{2}$ with a $\mathrm{Z}$ score of -5.8 .

The narrow medullary canal, which was about $3 \mathrm{~mm}$ wide at its most narrow portion, with the flexion deformity of $100^{\circ}$ of the knee made nailing of the femur an unfavorable option. Therefore, we fixed the fracture with a lag screw with a neutralization plate by a lateral approach (Fig. 4a). After 9 days of the procedure, the patient suffered from a proximal peri-implant stress fracture (Fig. 4b). We fixed this second peri-implant fracture by plating

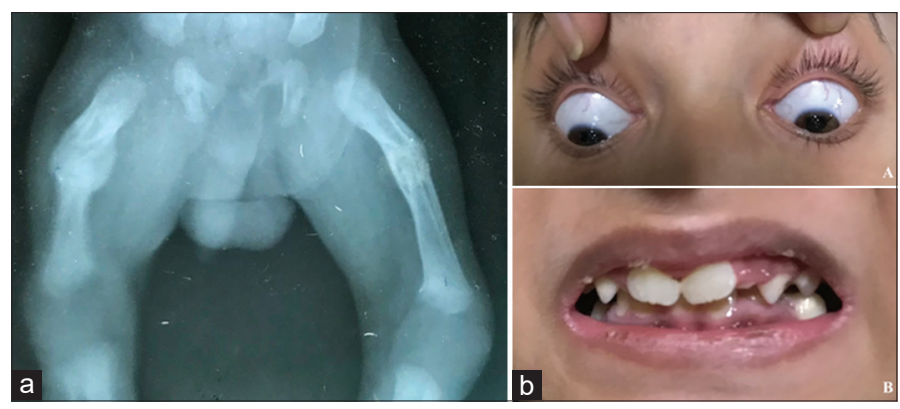

Figure 1: (a) Radiograph of bilateral thigh taken 15 days postpartum showing bilateral femoral shaft fracture with callus formation; (b) clinical photographs showing white ocular sclera (A) and normal appearing dentine (B)

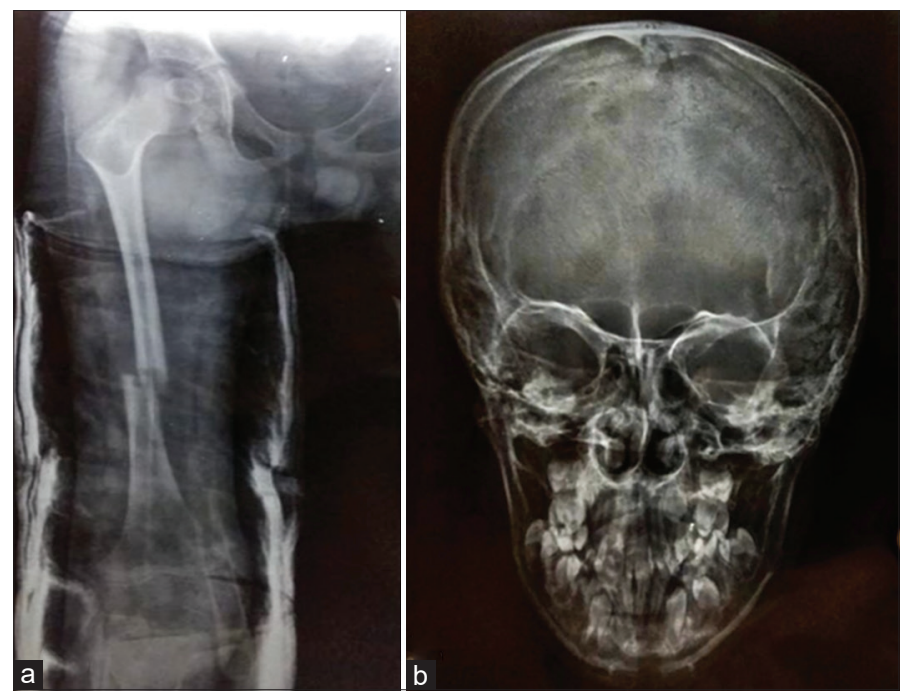

Figure 2: Radiograph of the (a) right thigh anteroposterior view showing midshaft femur fracture. The diaphysis can be marked to be narrow called the "gracile shaped appearance;" (b) skull anteroposterior view showing Wormian bones most appreciable over the left parietal area at the anterior aspect of the femur (Fig. 4c). After 1 month of the second surgery, the patient developed another fragility fracture (Fig. 4d). We finally managed the fracture non-operatively with a hip spica cast. The intravenous pamidronate injection therapy was initiated 6 weeks after the application of the hip spica cast. It was given in three divided doses $\left(7.5 \mathrm{mg}\right.$ on the $1^{\text {st }}$ day, and $15 \mathrm{mg}$ on the $1^{\text {nd }}$ and $3^{\text {rd }}$ day), each in $100 \mathrm{ml}$ normal saline infusion over 3 h every 3 months. Oral calcium and Vitamin D supplementation were also given to the patient. The bisphosphonate injection therapy was continued for 2 years.

The patient is in regular follow-up for the past 3 years. He sustained a fragility fracture in the contralateral limb 2 years after the initial presentation, for which he was managed non-operatively by a hip spica cast. Apart from this fracture, he did not sustain any other fracture. The right femur fracture got united, but the patient is still wheelchair-bound and is undergoing occupational therapy and regular physiotherapy for flexion contractures in the knee and ankle.

\section{DISCUSSION}

Bruck syndrome is a rare variant of osteogenesis imperfecta characterized by recurrent fracture and congenital joint contractures. Fractures in Bruck syndrome usually occur in the diaphysis of long bones such as the tibia and femur. However, fractures of other sites such as vertebra, ribs, and clavicle are also reported in the literature. The frequency of recurrent fracture in

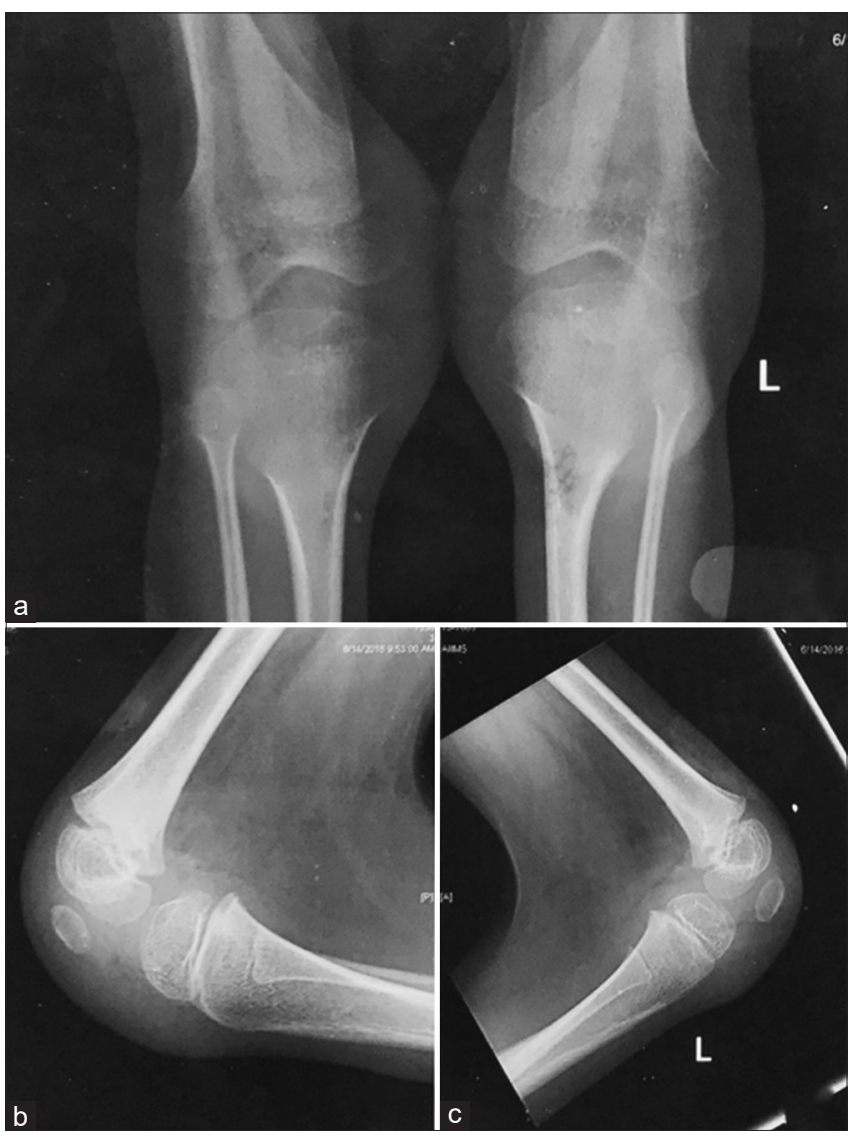

Figure 3: Radiographs of bilateral knee joints anteroposterior (a) and lateral (b and c) views showing the flexion contracture at both knees. The shadows of the pterygium can be marked in the lateral views 

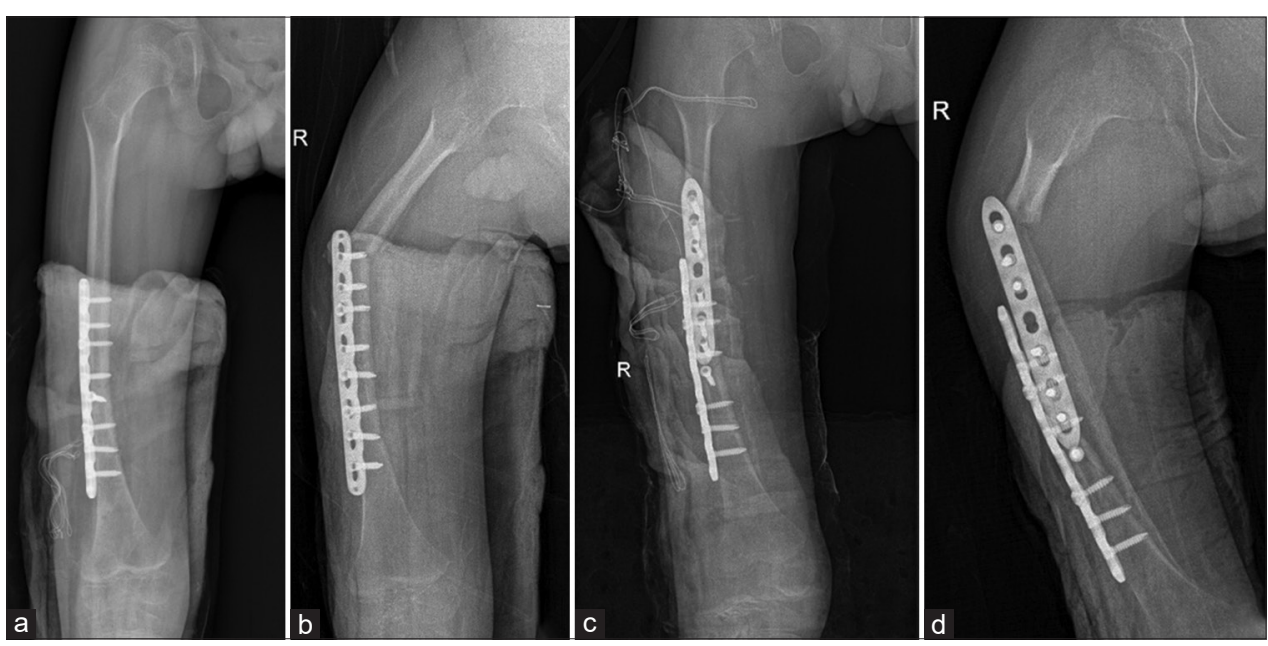

Figure 4: Radiographs of right thigh anteroposterior view. a: Radiograph was taken after the primary surgery where the fracture was fixed with the help of a lag screw and a locking compression plate (LCP). b: Radiograph taken after 9 days of the primary surgery, showing a peri- implant fracture at the proximal end of the plate. c: Radiograph showing the fixation of the stress fracture by a second LCP in compression mode applied over the anterior aspect of the femur. D: Radiograph taken after 1 month of the second surgery, showing a peri- implant fracture at the proximal end of the anterior plate

Bruck syndrome is highly variable. Our patient developed the first fracture, at the age of 7 years after the initial fractures which were sustained during birth. However, Luce et al. has reported the case of a male child with Bruck syndrome who had suffered more than 45 fractures by the age of 6 years [4].

Characteristic clinical features of osteogenesis imperfecta such as blue sclera, Wormian bones, hearing loss, dentinogenesis imperfecta may or may not be seen in Bruck syndrome. Few authors have reported blue sclera and Wormian bones [5-7]. Our patient did not have blue sclera, hearing loss, and dentinogenesis imperfecta, however, he had Wormian bones.

None of the authors in the literature have reported delayed union or non-union associated with Bruck syndrome. However, the management of these fractures is tricky due to joint contractures and a narrow medullary canal. Peri-implant stress fractures are also common in Bruck syndrome. We fixed the femoral shaft fracture with a plate twice, and the patient suffered from fractures proximal to the plate on both occasions. Enright et al. had also reported complications such as fracture, deformity, hardware failure, and non-union with plating in patients with osteogenesis imperfecta [8]. They along with Thomas et al. had advised avoiding plate fixation in these fractures to avoid implant-related fracture $[8,9]$.

One of the characteristic features of Bruck syndrome is the presence of congenital joint contractures. Due to the presence of these contractures, the patient is usually initially diagnosed as arthrogryposis multiplex congenita. In Bruck syndrome, joint contracture is commonly associated with pterygia. However, some authors have reported contractures without pterygia $[10,11]$. Large joints such as the knee, elbow, and ankle are commonly involved. Because of these contractures, the patient usually remains wheelchair dependent. The treatment of these contractures is also critical. Our patient received a serial cast for contracture correction but did not respond to treatment. Luce et al. had also shown the failure of contracture correction following serial casting and soft-tissue release [4].
Apart from joint contractures, many other deformities are also associated with Bruck syndrome. The deformity may be present in the thorax (barrel chest deformity and pectus carinatum), spine (kyphoscoliosis and spondylolisthesis), pelvis (Protrusio acetabuli), and foot (clubfoot and congenital vertical talus). Because of these deformities and contractures, the long-term prognosis of these patients is poor. Many authors have reported early death in Bruck syndrome patients with significant scoliosis and chest wall deformity due to respiratory failure [10-12].

Bruck syndrome is a clinical diagnosis wherein the patient presents with multiple metachronous fractures and joint contractures and is not associated with any specific genetic defect. The same mutation can manifest as Bruck syndrome in one patient and non-syndromic autosomal recessive osteogenesis imperfecta in another patient. FKBP10 and PLOD 2 mutations are the two most commonly reported mutations associated with Bruck syndrome. However, these mutations are not specific to Bruck syndrome, and patients with these mutations can also present with non-syndromic autosomal recessive osteogenesis imperfecta [10]. Shaheen et al. had shown that among four siblings of one Saudi family, all having the same FKBP10 mutation (homozygous C.743dupC), only one had Bruck syndrome while the other three had osteogenesis imperfecta [10]. Similarly, Luce et al. and Kelly et al. had also shown interfamilial and intrafamilial phenotypic variability of FKBP 10 mutation $[3,4]$. Hervas et al. had reported intrafamilial phenotypic variability among two brothers with the same PLOD2 gene mutation, where one had mild osteogenesis imperfecta, while the other had Bruck syndrome [13]. Mumm et al. have reported a patient with PLOD2 mutation as Bruck syndrome without any joint contracture [5]. In our understanding, the role of genetic analysis in Bruck syndrome is inconclusive, and its significance is yet to be defined. Therefore, we did not perform a genetic analysis on our patient.

Bisphosphonate is the mainstay of treatment of recurrent fracture in Bruck syndrome. Our patient suffered from only one 
subsequent fracture on the contralateral femur while he was on bisphosphonate therapy. Pamidronate and zoledronic acids are two intravenously administered drugs for these recurrent fragility fractures. Out of these, pamidronate is the most commonly advocated drug for Bruck syndrome. However, zoledronic acid is more convenient due to easier follow-up. Pamidronate is administered in divided doses for 3 days at the interval of 2-4 months [14], whereas, zoledronic acid is given biannually as a single dose [15].

\section{CONCLUSION}

From this case, we can conclude that patients of arthrogryposis multiplex congenita and those with congenital joint contractures with or without pterygium should be screened for Bruck syndrome. This case further affirms that in patients with fragility fracture plating is biomechanically inappropriate.

\section{REFERENCES}

1. Martin E, Shapiro JR. Osteogenesis imperfecta: Epidemiology and pathophysiology. Curr Osteoporos Rep 2007;5:91-7.

2. Santana A, Oleas-Santillán G, Franzone JM, Nichols LR, Bowen JR, Kruse RW, et al. Orthopedic manifestations of Bruck syndrome: A case series with intermediate to long-term follow-up. Case Rep Orthop 2019;2019:8014038.

3. Kelley BP, Malfait F, Bonafe L, Baldridge D, Homan E, Symoens S, et al. Mutations in FKBP10 cause recessive osteogenesis imperfecta and Bruck syndrome. J Bone Miner Res 2011;26:666-72.

4. Luce L, Casale M, Waldron S. A rare case of Bruck syndrome Type 2 in siblings with broad phenotypic variability. Ochsner J 2020;20:204-8.

5. Mumm S, Gottesman GS, Wenkert D, Campeau PM, Nenninger A, Huskey M, et al. Bruck syndrome 2 variant lacking congenital contractures and involving a novel compound heterozygous PLOD2 mutation. Bone 2020;130:115047.
6. Sharma NL, Anand JS. Osteogenesis imperfecta with arthrogryposis multiplex congenita. J Indian Med Assoc 1964;1:124-6.

7. Viljoen D, Versfeld G, Beighton P. Osteogenesis imperfecta with congenital joint contractures (Bruck syndrome). Clin Genet 1989;36:122-6.

8. Enright WJ, Noonan KJ. Bone plating in patients with Type III osteogenesis imperfecta: Results and complications. Iowa Orthop J 2006;26:37-40.

9. Thomas IH, DiMeglio LA. Advances in the classification and treatment of osteogenesis imperfecta. Curr Osteoporos Rep 2016;14:1-9.

10. Shaheen R, Al-Owain M, Faqeih E, Al-Hashmi N, Awaji A, Al-Zayed Z, et al. Mutations in FKBP10 cause both Bruck syndrome and isolated osteogenesis imperfecta in humans. Am J Med Genet A 2011;155A:1448-52.

11. Setijowati ED, van Dijk FS, Cobben JM, van Rijn RR, Sistermans EA, Faradz SM, et al. A novel homozygous 5 bp deletion in FKBP10 causes clinically Bruck syndrome in an Indonesian patient. Eur J Med Genet 2012;55:17-21.

12. McPherson E, Clemens M. Bruck syndrome (osteogenesis imperfecta with congenital joint contractures): Review and report on the first North American case. Am J Med Genet 1997;70:28-31.

13. Puig-Hervás MT, Temtamy S, Aglan M, Valencia M, Martínez-Glez V, Ballesta-Martínez MJ, et al. Mutations in PLOD2 cause autosomal-recessive connective tissue disorders within the Bruck syndrome-osteogenesis imperfecta phenotypic spectrum. Hum Mutat 2012;33:1444-9.

14. Andiran N, Alikasifoglu A, Alanay Y, Yordam N. Cyclic pamidronate treatment in Bruck syndrome: Proposal of a new modality of treatment. Pediatr Int 2008;50:836-8.

15. Otaify GA, Aglan MS, Ibrahim MM, Elnashar M, El Banna RA, Temtamy SA. Zoledronic acid in children with osteogenesis imperfecta and Bruck syndrome: A 2-year prospective observational study. Osteoporos Int 2016;27:81-92.

Funding: None; Conflicts of Interest: None Stated.

How to cite this article: Jain G, Datt R, Sharma V, Farooque K, Morankar R, Krishna A. Bruck syndrome: A rare case presentation with isolated lower extremity contractures and multiple postoperative peri-implant fractures. Indian J Case Reports. 2021;7(11):473-476. 